\title{
19
}

\section{Work-Life Integration: Challenges and Organizational Responses}

\author{
P. Monique Valcour and Rosemary Batt
}

\begin{abstract}
I wish there were more flexibility, especially in our production environment. I've worked all my life around the rotating-work schedule, but this year alone I lost three excellent employees. They had each become single parents for one reason or another, and there's no way you can get child care in off hours and weekends. It just breaks my heart. Traditionally production has been a male-oriented thing, where one partner stays at home with the children and the other one works crazy schedules.... the world is changing, but the schedule is not.

-Manufacturing production supervisor married to part-time educational coordinator and father of two children ages 8 and 14
\end{abstract}

his chapter focuses on organizational responses to the challenges
dual-earner couples face in integrating their work and family lives. We examine the effectiveness of various workplace characteristics and organizational initiatives for supporting work-life integration. We then develop a comprehensive model of organizational family responsiveness that incorporates work-life policies, traditional human resource incentives, and work redesign in the context 
of a workplace culture that facilitates the full implementation of these policies. We then test some of the components of this model as predictors of outcomes of interest to both workers and employers. Specifically, we assess the effects of formal policies and supervisor support for flexible work arrangements, traditional human resource incentives, and work-design measures on work-family conflict, perceived control, and turnover intentions. We do this within the context of dual-earner couples in The Cornell Couples and Careers Study, which enables us to take into account the characteristics of both spouses' jobs and workplaces. ${ }^{1}$

\section{The Challenges of Work-Life Integration}

Employees have traditionally faced the challenge of meeting the competing demands of work and family life with the assumption that they were solely responsible for managing their own balancing acts and could not expect significant assistance from their employers in this regard. ${ }^{2}$ Both employers and employees often treated work and family domains as separate spheres of existence. ${ }^{3}$ Typical of this presumption is a statement by an executive in the early 1990s: "Competent workers can handle work-family problems and there is nothing a company can really do to help the incompetent workers." ${ }^{4}$ Similarly, in Arlie Hochschild's study of a supposedly family-friendly workplace, female executives avoid placing family photographs in their offices, and the norm of long work hours as a display of organizational commitment is dominant. ${ }^{5}$

Employees tend to experience work-family conflict when demands from work and family are both high and difficult to satisfy. Work-family conflict is a form of interrole conflict in which incompatible demands emanating from work and family domains make it difficult or impossible to satisfy both sets. ${ }^{6}$ Employees from dual-earner families (the subjects of our study) are particularly likely to experience conflict between work and family. ${ }^{7}$ Whereas most research has focused on individuals and the work-family conflict they personally report, a growing number of studies suggest that work-life issues must be understood in the context of both spouses' employment conditions. One study, for example, documents crossover effects from husbands' and wives' work schedules to family life, ${ }^{8}$ and a 1988 study finds that husbands and wives in dual-earner couples restructured their work lives to accommodate family partly based on the job characteristics of their spouses. ${ }^{9}$ A 1991 study finds relationships among employees' job security, income, and weekly work hours and their spouses' job involvement and satisfaction. ${ }^{10} \mathrm{~A} 1999$ study using data from The Cornell Couples and Careers Study reports that couples devise joint strategies for managing the demands of two careers, often by scaling back the demands of one spouse's job. ${ }^{11}$ Hence, in our analysis, we assess the effects of spouses' employment conditions on one another's reported work-family outcomes. 
Evidence for the deleterious effects of work-family conflict on individuals, families, and organizations has been building (see Roehling, Moen, and Batt, chap. 7 in this volume). Research suggests that dual-career couples are very concerned about work-life integration and committed to preserving time with their family. ${ }^{12}$ Both quantitative and qualitative research suggests that many workers feel their employers could be-and should be-much more family responsive. ${ }^{13}$ Some companies have responded to employee demands for better work-life integration as a critical component of recruitment and retention strategies. ${ }^{14} \mathrm{~A}$ few firms are beginning to link family responsiveness to overall corporate strategy, particularly as a component of work quality and productivity improvements. ${ }^{15}$

Research has begun to document the positive outcomes of corporate work-life initiatives. ${ }^{16}$ Through such programs as flexible work arrangements, reduced work time, dependent care, financial benefits, and culture-change initiatives, companies can reduce employees' work-family conflict, ${ }^{17}$ improve their job satisfaction, ${ }^{18}$ and improve elements of corporate performance including absenteeism ${ }^{19}$ and retention. ${ }^{20}$ But the research documents more positive outcomes for employees $^{21}$ than for employers, for whom findings are more mixed. ${ }^{22}$ In our quantitative analysis in this chapter, therefore, we examine outcomes of interest to employees (work-family conflict and employee control over work-family integration) as well as employers (employee-turnover intentions).

\section{The Dimensions of Organizational}

\section{Family-Responsiveness}

Early studies of work and family focus on programmatic initiatives for dependent care, flexible scheduling, and the like. Over time, researchers have increasingly recognized the limitations of programmatic initiatives for responding to nonwork demands and have focused on a wider range of workplace conditions, including work design and workplace culture. There is, however, no general consensus on what, in fact, constitutes a family-responsive work environment. In this paper, we develop a comprehensive model of organizational strategies for worklife integration. We use the term "family" as shorthand to signify the demands employees face from the nonwork arena. Thus, we recognize that all employees, not only those with spouses and children living at home, experience the demands that result from personal relationships and involvements outside of the workplace. In our view, a family-responsive employer recognizes, legitimates, and responds to the challenges of integrating work and nonwork demands for employees at all stages of their family life cycle. A family-responsive employer provides:

- A broad range of work-life programs that provide employees with control over their working time and support in meeting their family and personal needs 
- Adequate pay, benefits, and employment security

- Work designed to provide employees with discretion and control in meeting work and life demands

- A workplace culture, transmitted formally by organizational policies and informally by supervisors and coworkers, that values and supports the worklife integration of all employees

With respect to formal work-life policies, we include dependent-care policies as well as those designed to create greater flexibility in working time. Inflexible schedules and excessive work hours consistently produce conflict between work and family. ${ }^{23}$ Working time policies constitute a range of approaches to flexible schedules as well as those designed to reduce total work hours. Specific policies include flextime, family leaves, dependent-care time, time off for volunteering, compressed workweeks, job sharing, part-time work, and telecommuting. ${ }^{24}$ Employees from dual-earner families value flexibility highly; ${ }^{25}$ some are even willing to switch jobs to have more. ${ }^{26}$

The role of supervisors is particularly important in implementing formal flexible scheduling and work time policies as well as informal working arrangements and schedules. Supervisors are responsible for staffing levels, allocation of work assignments, and unit output. Although supportive supervisors often can allow more flexibility than exists in the written policies of the organization, unsupportive supervisors can subvert employers' family-friendly policies. ${ }^{27}$ Thus, companies must train supervisors and create a workplace culture that facilitates consistent policy implementation.

The second dimension of a family-responsive workplace is adequate employment and income security. Historically, employers used pay, benefits, and promotion opportunities to reduce turnover and induce long-term commitment to the firm. These policies, or internal labor-market rules, protected (mostly male) breadwinners (and their families) from the vicissitudes of competitive labor markets. ${ }^{28}$ Such policies provided the kind of employment security and income growth that create family stability. ${ }^{29}$ Thus, high pay and benefits, employment security, and career development opportunities should create an environment in which employees view their employers as supportive of family needs and demands. Ironically, however, at a time when employers have begun to initiate family-friendly policies, many have simultaneously undertaken policies of downsizing, outsourcing, and contingent staffing in order to reduce pay, benefits, and a commitment to long-term employment relations.

The third dimension of a family-responsive workplace comprises work designed to allow employees to meet their work and nonwork demands on a daily basis. Flexible scheduling policies have proven insufficient to meet these needs. For example, a nationally representative survey of nearly three thousand employees found that working parents experience less work-family conflict when they 
have jobs with greater autonomy, more schedule control, and fewer demands. ${ }^{30}$ By contrast, formal family-friendly policies had no effect on reported levels of work-family conflict for these employees. Autonomous work design not only leads to higher levels of motivation and satisfaction, ${ }^{31}$ but also signals to employees that they are trusted to get their work done and manage their time effectively. ${ }^{32}$ Employees who report greater control over managing work and family demands also report lower work-family conflict, more job satisfaction, and fewer physiological stress-related symptoms. ${ }^{33}$

Employers often worry, however, that greater individual autonomy simply undermines productivity. Some research by Lotte Bailyn and others, however, suggests otherwise. ${ }^{34}$ Bailyn's research group undertook intervention projects at three corporations in the early 1990s. In one case, a team of productdevelopment engineers at Xerox worked in an environment that emphasized long hours and "face time" as a sign of commitment to the employer. Long meetings, documentation requirements, and the interference of supervisors in the day-today work of the engineers meant that the real work of product development took place before or after daytime work hours, thereby creating a vicious circle of longer hours, high stress, and low productivity. The intervention team examined time use and redesigned the work so that supervisors were severely restricted in the time they could interact with the engineers. As a result, the engineers increased their autonomy and control over work routines and schedules, substantially increased their productivity, and decreased their total work hours.

The relationship between work-life integration and other dimensions of work design is more ambiguous. For example, firms have increasingly adopted more collaborative or team-based forms of work organization to improve workplace quality, efficiency, and coordination. Although there is considerable support for the idea that team collaboration and coordination improve organizational performance, ${ }^{35}$ there is little research on how these forms of work organization affect employees' ability to manage work and family. On the one hand, the ability to collaborate or coordinate work with other colleagues may increase flexibility if coworkers are able to substitute for one another or establish norms of reciprocity in which they agree to help one another meet work and nonwork demands. Some studies have found positive effects of team-based systems on work-life outcomes. ${ }^{36}$ On the other hand, the demands of collaboration and group coordination may increase work hours or the rigidity of work if they lead to time-consuming meetings or heightened peer-group pressure. ${ }^{37}$

The use of information technology is another area of work design that is rapidly changing, and the nature of its impact on work-life integration is also unclear. Portable computers, faxes, voice mail and email allow workers to bring work into the home more easily, but may have effects that are similar to those of telecommuting. Researchers have found very mixed outcomes for telecommuting because, although it increases flexibility, it also allows work to invade or spill over into home 
life more. As Noelle Chesley, Phyllis Moen, and Richard Shore (chap. 14 in this volume) describe, the little research on this aspect of work design has produced ambiguous findings on the effects of technology on the work-life interface. ${ }^{38}$ Accordingly, we include a measure of information technology use in our analyses.

Finally, the workplace culture in general must support and legitimate employees' nonwork role demands. This environment shapes the attitudes of managerial as well as nonmanagerial employees. For example, Susan Eaton, in her 2000 study of five hundred technical and professional employees in biotechnology firms, found that formal and informal family-friendly policies and benefits increased organizational commitment and satisfaction only to the extent that employees felt free to use the policies without detriment to their workplace relations or career success. ${ }^{39}$

The organization must also create an environment that recognizes variation in the work-life interface of employees over their life course. Parents experience more work-family conflict than nonparents, ${ }^{40}$ and thus need to be given special attention. However, to the extent that employers view work-life policy as focused on parents (particularly women) and privilege them over other employees who are single or whose children are grown, employers risk creating divisiveness at work. ${ }^{41}$ Accordingly, in this chapter we frequently use the term "work-life" rather than "work-family" to signify that employees, both male and female, of all family structures and life stages have legitimate demands on their time, energy, and psychological involvement from domains outside of their jobs.

\section{Qualitative Evidence from The Cornell Couples and Careers Study}

Our field research includes a series of focus groups involving 114 employees in our seven participating organizations. The demographic profiles of the focusgroup participants mirrors those of the survey respondents. Employees' supervisors were not present at the discussions, which were structured to cover the following three broad open-ended questions. First, what are the challenges you face and the strategies you use in combining work and family? Second, what arrangements (e.g., formal policies or informal arrangements) does your employer offer to help you combine work and family? Also, what arrangements have you used, what have you not used and why, and what has been helpful? Third, what would be ideal for you in terms of combining work and family?

Our results are based on a textual analysis of the focus-group transcripts, which involved coding passages relating to work-life support offered by the organizations. Table 19.1 provides frequencies for the thematic codes we have identified. The statements from the focus groups highlight the importance of flexible working time arrangements. They emphasize the utility of such policies as the 
Table 19.1 Frequency of Themes in Focus Group Transcripts

Themes Related to Work-Life Policy

Frequency

\section{Access to Flexible Working Time}

No company policy on flextime; up to supervisor discretion; varies by

department/supervisor

My department/supervisor is flexible

In my department, flexibility is handled informally (e.g., leave if you need to,

make the time up later)

My department/supervisor is not flexible

Flextime can make it difficult to coordinate work and manage the department

Flexibility is difficult because of lack of coworker support

Family leave policy helpful

Higher-level employees have more flexibility

Being able to use vacation time in small chunks for family needs is helpful

Lack of flexible work policies signals lack of investment in employees

\section{Total Work Hours and Workload}

The company has work-life policies, but the reality is it is hard to use them because

of work demands

The main problem is that we are asked to do too much work (due to downsizing and being understaffed)

Ability to work part-time is a helpful work-life policy

Ability to job-share is a helpful work-life policy

\section{Wages}

Organization should pay us more; that would be a family-friendly policy

Unpaid leave is not helpful because people cannot afford the loss of wages and benefits

\section{Dependent Care}

Dependent care time is a helpful policy

\section{Culture}

The culture does not support use of work-life policies

ability to leave in case of emergencies to attend to family needs, to arrange work schedules to accommodate family demands, and to do part of their work at home. School holidays, children's illnesses, or breakdowns in child-care arrangements are particularly problematic for the dual-career families in this study if neither parent has access to flexible scheduling. The comments also reveal the resentment felt by employees due to unequal access to flexible working time. A second related theme concerns the negative effects of long work hours and overly demanding workloads, which undermine the benefits of flexible work arrangements or other work-life policies. A third thematic area is the need for adequate pay and benefits. In sum, although many employees report being able to make individual flexibility arrangements with their supervisors, a wide range of critical comments from employees indicates dissatisfaction with overall organizational support for work-life integration. 


\section{Access to Flexible Scheduling}

A dominant theme in the focus groups is that the companies either have no formal policies for flexible scheduling or make the implementation of formal policies contingent on supervisor approval and that, as a result, access to such scheduling is unequal, arbitrary, and often insufficient. Unequal access derives from several sources, including variation in departmental tasks, the nature of work and technology, occupational differences, and supervisor attitudes. Interdepartmental variability is a persistent theme running through the focus-group discussions. For example, a professor with two grown children describes the extent of variation among departments at Upstate University:

There's a lot of variation from one area to another. I didn't realize just how much variation until I ended up on a committee last year that was looking at some of the things like flex time. Well, we were informed that there is no flex time. There is no comp time. However, in reality, I've been very fortunate to work for a department all these years that is very flexible and very humane, and kind of just does its own thing. It's sort of a "don't ask, don't tell" kind of thing. And what happens as a result is that people are fiercely loyal and grateful to their supervisor.

Other focus-group participants emphasize technological and occupational sources of variation. One Transco manager explains that he feels caught between company rhetoric emphasizing family supportiveness and manufacturing technology that has to be run on a rigid schedule:

To a certain extent I think it's lip service. These family-friendly policies are nice on paper, but a lot of them are hard to implement. I as a supervisor can't always implement what the company has set up, so I think we are setting people up with unrealistic expectations, and then sometimes we can't follow through on them. Like I had a guy in my group who wanted to do flex time and flex to the second shift, but it would've been very difficult to do. I really made an effort, but we needed two people in the department doing what he did on first shift.

Another Upstate University professor in her mid-forties (the mother of four school-age children, married to a computer programmer) observes, "I think a lot of it has to do with whether you're faculty or staff. As a faculty member, I've always felt a great deal of freedom. But there are a lot of people who are strictly hourly wage people who don't have near the flexibility in trying to do the kinds of things that we can do. So it's really two different worlds in the same office."

These statements are consistent with past research showing that workers with higher wages and occupational status have a wider range of flexible benefits than their lower-wage counterparts. ${ }^{42}$ 
Variation in access, however, can also occur among people in the same department or occupational group, based largely on the arbitrary discretion of supervisors. For example, a forty-year-old female part-time marketing specialist at Utilco with a preschool child reports, "My manager allows me to work part of my time at home, whereas some others don't. My situation hasn't gone through Human Resources and probably shouldn't, because it probably wouldn't get approved."

Although many employees rate their own supervisor favorably, they go on to cite other examples of inequitable treatment. Also, although employees are grateful for the flexibility that they have personally negotiated, informal deals come at a price-employees feel beholden to supervisors, who expect a return for their favors. As one mother of two in her late thirties employed by Lake University states:

We've talked about flexibility, but it's all based on what your supervisor is willing to allow you to do. And that puts you in a mode of groveling, begging, feeling anxious about whether it's going to be okay. You worry about how you might end up paying for it later. At some point down the road somebody is going to say, "you know, we gave you all the breaks." Since it's not a formal policy, it's seen as a privilege rather than as a right, and there's a big difference there.

These informal deals can create hard feelings or resentment from other employees who do not receive such special treatment, leading to divisiveness at work. Informal approaches to flexibility also lack the symbolic stamp of programs developed and supported by the organization. If employees and their supervisors believe that the only way they can accommodate work and family demands is by circumventing employers' rules and regulations, then it is likely that a breakdown of respect and trust will occur between employer and employee. This erosion of trust could, in turn, undermine morale and commitment to the organization. A 48-yearold man working for Utilco as a systems engineer notes, "A real flextime policy would be a part of a covenant in that it would be a formal recognition by management that we are professionals who do our work. When things need to be done, we're here, regardless of the time. Yet all the company has is the paternal system where your boss is the one who decides whether you'll have this flexibility."

All in all, the lack of formal policies for flexible working time not only limits access but leads to the development of informal deal-making between employees and their supervisors and to divisions and perceptions of inequality among employees who do and do not gain access to privileged schedules.

\section{Access to Reduced Work Hours and Workloads}

Excessive work demands also make for a family-unfriendly work experience, even when employers have work-life policies on the books. Although flexible 
schedules help solve work-life integration when total work hours are reasonable, excessive work hours, no matter how flexibly allocated, are likely to interfere with family and personal life. ${ }^{43}$ Employees in companies that have downsized or that emphasize "face time" and prioritize work above all else typically have more complaints about workplace inflexibility and heightened work-family conflict. A Transco production planner with a schoolteacher wife and grown daughter explains, "You've got the workload of two people, but it's all on you. All these programs are coming in, but forget the programs, just think about what's a realistic expectation without causing me to leave this job."

A colleague from the planning department (a father of three, married to a medical transcriptionist, with a live-in parent) seconds this opinion, "We don't need an employee assistance program, we need more employees!" Similarly, a forty-eight-year-old Vantech software engineer, married to a CPA and mother to one middle school and one college student, explains that she officially works parttime with a lower salary and reduced benefits so she can, in fact, limit herself to a regular full-time (forty-hour) workweek: "The hours we are expected to work just seem to grow and grow. I'm part-time, 32 hours a week. Now that my kids are older, I would be more ready to go to 40 , but once you officially work 40 , then they expect you to work 60 . So if I say I'm working 32 , most of the time I end up working 40 , but at least it stops at $40 . "$

Focus-group participants feel that a family-responsive employer would guard against the tendency for work time to expand without limit. Although employers alone do not determine how much time employees spend at work, ${ }^{44}$ they set staffing levels, expectations, and demands. A female engineer with two teenage children and twenty-four years of service to Vantech comments, "It used to be you were working really hard if you worked 50 hours a week. Now this is just adequate, and the new buzz word is to say you work 60 hours a week. I think there is something wrong with that, and businesses should stop promoting it. I think that this company can do something about changing the perception that you're not a professional unless you work 60 hours a week."

Past research shows that employers' efforts to set limits on the workday can reduce employees' work-family conflict and even improve corporate productivity. ${ }^{45}$ In some focus groups, employees identify these types of efforts as important organizational strategies to support work-life integration. A Vantech production supervisor in his late thirties with two school-age children says, "I think the company should step up to the plate and address the issue of how many hours a week people actually work. We should not allow the demands of work to creep beyond 50 to 60 hours-where does it stop? The company needs to step in and put some limits in effect, because otherwise it will continue to creep."

Other solutions include job-sharing or part-time arrangements, but these options are not widely available to employees at the seven participating organizations in The Cornell Couples and Careers Study. Individual employee initiative is the common catalyst for these types of arrangements, and some 
professionals are able to reduce hours through negotiations with their supervisors. One Upstate University administrator with two children (ages three and six) explains her situation: "I job share with another professional. It works great, but I had to write up a proposal for it and work it out with my boss. We worked together to go forward on it."

Another Transco planning specialist, a mother of a nine-year-old and fouryear-old twins and married for fifteen years to a business administrator, describes her efforts to set up a job-sharing situation and her feeling that she is lucky to have succeeded:

I was lucky to work out a job sharing arrangement because there was another woman in my department who did the same thing as me and was also struggling after she had her second baby. So we went to the human resources person and she was supportive but said the company doesn't have this in place. So we did the research and went to the president of the division and we went through a couple of struggles, but eventually they accepted it. I'm so glad it worked out, because it's been great for me and my family.

However, as in the case of flexible schedules discussed previously, individually negotiated deals to reduce work hours create divisions among employees and perceived inequality at work. Some employees are not successful in their negotiations. For example, a Citizen's Health senior account executive with two children describes her experience: "I had a job-sharing arrangement when my first child was little, but I now have a two-year-old and the company won't allow me to do this. I think that when the company was smaller, they were willing to work with us, but now that we've grown to be a bigger organization, they just don't do that. And they're really strict with the hours. I asked if I could work 8-4:30, but they weren't willing to do that."

Similarly, a forty-five-year-old Vantech information systems manager, married to a lab technician and with two grown children, expresses his frustration with the lack of organizational consistency regarding reduced working time arrangements:

With job sharing and part time, it's not consistent throughout the company. There are some areas where if you say you want to go part time, they'll say either work full-time or you have no job. They don't give you the flexibility even though if you look at the structure of your job and what is required for the position, you could easily do that on a part time basis, or by taking part of the work home if need be.

In sum, focus-group participants highlight the need for reduced work hours as part of an overall flexible working time policy. In the absence of such policies, 
workers push for individual exceptions to rules, leading to perceptions of inequality between the haves and have-nots.

\section{Beyond Work-Life Policies and Informal Supports}

Thus, increasing the apparent flexibility of a job or career while still expecting workers to commit boundless time and energy to work does little or nothing to advance the cause of work-life integration. ${ }^{46}$ Note that the professionals in our study tend to enjoy job autonomy and control over their work, but also experience conflict between work and nonwork life.

Formal and informal work-life policies alone do not address the full range of challenges that working families face in trying to successfully integrate work and the rest of life. Job security, pay, career-development prospects, benefits, and other job features that are important to employees and their family stability are also components of organizational family responsiveness. ${ }^{47}$ Several focus-group participants frame the issue of compensation in terms of its impact on the worklife interface. A forty-six-year-old Utilco engineer, father of two teenagers and married to a nurse, says:

I haven't had a pay raise in three years, and that may appear to be a personal "bitch," but it has a tremendous impact on the family and the strain. I honestly feel that it falls very closely in line with the theme of what we're talking about here. And also, every year for benefits, we get a smorgasbord of options, but they're all reduced. They've gone down for the last five years now. We've been forced into an HMOtype medical benefit, and our cost has increased. That impacts on your family life because it impacts on your budget. And also on the quality of medical care you and your family get.

Repeated comments among focus-group members also emphasize the importance of embedding work-life policies in an overall organizational culture that validates and respects employees' needs to reserve time and energy for nonwork activities. Themes of respect, trust, and employee empowerment were recurrent, as in the statement of a Vantech chemical engineer in her thirties with an elementary school child: "I think there needs to be an environmental shift for people to say that we really do embrace people who have families that are important to them, that they can still be very good workers and excellent contributors, and we will work with them so they can manage well with work and with family. And I don't know how you do that in a policy; it's more of a complete shift in thinking."

The overall conclusion that we draw from our review of the qualitative data is that formal work-life policies alone do not make a family-responsive employer. 
The design of human resource practices, the organization of work, and the overall culture regarding the relative importance of employees' work and nonwork lives form the backbone of an integrated approach to work-life balance.

\section{Quantitative Results from The Cornell Couples and Careers Study}

We now turn to survey data of a subsample of couples from The Cornell Couples and Careers Study and use regression analysis to investigate the predictors of work-family conflict, control over work circumstances, and individuals' intention to leave their present employer. We report results from 264 married or cohabiting opposite-sex couples in which both members are employed. This subsample, approximately one-third of the overall Cornell study, represents participants who were randomly administered the module of survey questions containing the measures of job and workplace characteristics. (For a description of the overall sample, please see app.)

\section{Measures}

Dependent Variables We have three dependent variables: work-family conflict (negative spillover from work to family), employee control over work, and intention to quit one's job. The first two measures capture individuals' dayto-day ability to manage time and commitments to work and family.

Work-family conflict. This is a two-item scale of negative spillover from work to family (see Roehling, Moen, and Batt, chap. 7 in this volume, for source and wording of items).

Employee control over work. To measure this, we asked employees how much choice they have over their daily work schedule, weekly work schedule, their use of vacation and personal time, their ability to receive personal phone calls and email at work, the amount and timing of work that must be done at home in order to meet work demands, and the place at which they work (home versus regular workplace). The scale (alpha $=.76$ ) is adapted from Linda Thomas and Daniel Ganster. Responses are measured on a scale of $1-5 .^{48}$

Intention to turn over. This is measured by a scale score comprising five items that ask whether respondents plan to stay with their present employers until retirement, how many more years they expect to stay, whether they have recently talked to colleagues or friends about looking for another job, 
whether they are actively looking for another job, and whether they are seriously considering quitting.

Independent Variables Independent variables include three measures of traditional human resource incentives, two measures of formal and informal work-life support, and five work-design measures.

\section{Human Resource Incentives}

Salary. This is measured with a single item based on the question: "What is your annual salary from paid employment, including any bonuses, overtime, and/or commissions, before taxes and other deductions?"49

Job security. This is based on respondents' answer to: "Think of a scale of 0 to 100 , where 0 means you are certain you will lose your present job and 100 means you are certain you will be able to keep it. How certain is it that in the next couple of years you will be able to keep your job?"'

Career development benefits. This is measured by an additive index of three types of career support: education and training, tuition reimbursement, and career-development services.

\section{Formal and Informal Work-Life Support}

Flexible scheduling policies. This is an index measuring whether employees are granted five types of benefits relating to the flexible use of work time: paid family leave, personal/dependent-care time (small increments of time off during work hours to attend to personal or family needs), flextime, telecommuting, and time off for volunteering. Note that we measure availability, not use, of flexible scheduling policies. ${ }^{50}$ The variable takes on values ranging from 0 (have none) to 5 (have all five).

Supervisor support. This is a four-item scale based on the following items: how frequently in the past three months employees' supervisors have switched schedules to accommodate their family responsibilities, have listened to their problems, have juggled tasks or duties to accommodate their family responsibilities, and have shared ideas or advice. Responses range from 1 (never) to 5 (very often). The alpha reliability coefficient is $.68 .^{51}$

\section{Work-Design Measures}

Decision-making autonomy. This is a scale based on the following three items: "I determine what I need to do in order to complete my assignments," "I am able to influence what procedures, tools, and material I use in doing my 
work," and "I am able to influence which specific tasks I am assigned to do." The response format was a scale of $1-5$, where $1=$ strongly disagree and $5=$ strongly agree. The alpha reliability coefficient for this scale is .68.

Coordination. This is a three-item additive scale that measures how frequently employees coordinate with colleagues in their own departments, colleagues outside of their departments, and managers or supervisors in their departments in order to accomplish their work tasks. ${ }^{53}$

Flexible technology use. This is an additive index of six items that measure employees' use of email, beepers, cellular phones, or fax machines to communicate with work while at home or with home while at work and the use of a portable computer or home computer to do work.

Work hours. This is a single-item measure that asks employees, "On average, how many hours a week do you actually work, including any paid or unpaid extra hours that you put in beyond your official work week?"

Travel. This is a dummy variable that measures whether the respondent is required to do overnight travel as a regular part of the job.

\section{Control Variables}

Children. This is the number of children living in the home. It is likely that having children will be positively related to work-family conflict and negatively related to perceptions of control over managing work and family matters.

Affect. This is a five-item scale used to control for negative disposition or affect. ${ }^{54}$ Employees rated how frequently in the past month they have felt in good spirits (reverse scored), so sad that nothing could cheer them up, restless or fidgety, nervous, or that everything was an effort. Coefficient alpha for this measure is .61 .

Age. This is self-reported and should be negatively related to turnover intentions.

Job tenure. This measures the number of years that employees have been in their jobs.

\section{Results}

Mean Levels of Work-Family Conflict, Employee Control over Work, and Turnover Intentions Most of our husbands and wives report experiencing work interference with family at least some of the time; the mean for both groups is approximately 2.7 on a scale of 1 to 5 , with 1 representing "never" and 5 representing "all of the time." Eighty-one percent of wives and 72 percent of husbands report that their jobs make them feel too tired to do the things that need 
attention at home at least some of the time. Fifty-seven percent of wives and 67 percent of husbands report that job worries distract them while they are at home at least some of the time. Both wives and husbands report having a fair amount of control over their work circumstances, with husbands reporting slightly higher levels-a mean score of 3.6 on a scale of 1 to 5 versus 3.2 for wives. Approximately two-thirds of the employees in our sample have no plans to leave their current employers. Slightly more husbands than wives do intend to change employers before they reach retirement.

Results from Regression Analysis Table 19.2 presents the results (coefficients and overall model fit) of the regression analyses of work-family conflict, employee control over work, and turnover intentions for wives and husbands, respectively. For ease of interpretation, we present standardized beta coefficients for the models of work-family conflict and control over work, which were estimated using ordinary least squares (OLS) regression. The figures in the columns under Turnover Intentions are coefficients from ordered probit models. The predictors, which are grouped into sets, include three of the four dimensions of organizational family responsiveness identified in the introduction to this chapter (formal and informal policies for work-life support, traditional human resource incentives, and work design), spouse's work characteristics, and control variables. We discuss the findings for each set of predictors for all three dependent variables. We present results for wives and husbands separately because in models using the full sample, the coefficient for an indicator variable for gender was significant in regressions of all three outcomes. Gender is a key consideration, not only because past research has documented differences in the level and nature of work-family conflict experienced by women and men, but also because some research reports that women have higher levels of turnover than men.

Concerning policies for work-life support, access to flexible scheduling has surprisingly little impact on the work-family outcomes tested. It has no effect on the work-family conflict or the reported control over work of either wives or husbands. It is negatively related to turnover intentions, but this relationship holds only for husbands. By contrast, supervisor supportiveness has a strong negative effect on wives' work-family conflict and is negatively related to both wives' and husbands' turnover intentions. Thus, women whose supervisors support their efforts to integrate work and the rest of life experience lower levels of workfamily conflict, and both women and men who enjoy supervisor support are less likely to quit their employers.

Traditional human resource incentives (salary, job security, and careerdevelopment benefits) affect all three outcomes. Salary is positively related to both work-family conflict and control over work for husbands; this seemingly paradoxical effect may signify that highly paid jobs are likely to both impose extensive demands on their incumbents and also grant them a high level of control 
Table 19.2 Regressions of Work-Family Conflict, Control over Work, and Turnover Intentions ${ }^{a}$

\begin{tabular}{|c|c|c|c|c|c|c|}
\hline & \multicolumn{2}{|c|}{$\begin{array}{c}\text { Work-Family } \\
\text { Conflict }\end{array}$} & \multicolumn{2}{|c|}{$\begin{array}{l}\text { Control over } \\
\text { Work }\end{array}$} & \multicolumn{2}{|c|}{$\begin{array}{l}\text { Turnover } \\
\text { Intentions }\end{array}$} \\
\hline & Wives & Husbands & Wives & Husbands & Wives & Husbands \\
\hline \multicolumn{7}{|l|}{ Work-Life Support } \\
\hline Flexible scheduling & -0.08 & 0.04 & -0.04 & 0.02 & -0.20 & $-0.32 *$ \\
\hline Supervisor support & $-0.27 * * *$ & 0.03 & 0.05 & 0.02 & $-0.62^{*}$ & $-0.75^{*}$ \\
\hline \multicolumn{7}{|l|}{ HR Incentives } \\
\hline Salary $(\log )$ & 0.05 & $0.16^{*}$ & -0.02 & $0.27 * *$ & -0.53 & -0.63 \\
\hline Career development & 0.04 & 0.07 & -0.04 & 0.04 & 0.35 & 0.36 \\
\hline Job security & $-0.14^{*}$ & $-0.15^{*}$ & 0.04 & 0.00 & $-0.02 *$ & $-0.04 * * *$ \\
\hline \multicolumn{7}{|l|}{ Work Design } \\
\hline Decision autonomy & -0.01 & -0.05 & $0.26^{* * *}$ & $0.17 * *$ & 0.27 & 0.00 \\
\hline Coordination & 0.07 & $0.13^{*}$ & -0.07 & $-0.11^{\dagger}$ & 0.07 & 0.05 \\
\hline Flexible technology & $0.12^{\dagger}$ & 0.05 & $0.35^{* * *}$ & $0.36 * * *$ & 0.19 & $0.25^{\dagger}$ \\
\hline Work hours & $0.15^{\dagger}$ & 0.05 & $-0.17 *$ & $-0.19 * *$ & -0.02 & -0.02 \\
\hline Travel & 0.04 & -0.06 & $0.20 * *$ & $0.18 * *$ & $0.74^{\dagger}$ & 0.13 \\
\hline Control over Work ${ }^{b}$ & & & & & -0.40 & $-0.81^{* *}$ \\
\hline \multicolumn{7}{|l|}{ Spouse Variables } \\
\hline Work hours & -0.02 & -0.08 & 0.08 & 0.05 & 0.03 & -0.01 \\
\hline Salary $(\log )$ & -0.03 & 0.01 & -0.04 & 0.03 & $-1.18 *$ & 0.37 \\
\hline Job security & 0.00 & 0.02 & 0.05 & 0.01 & 0.00 & 0.00 \\
\hline Flexible technology & 0.00 & -0.03 & -0.08 & $-0.14 *$ & 0.12 & 0.14 \\
\hline Flexible scheduling & 0.00 & -0.02 & -0.05 & -0.04 & 0.06 & $-0.24^{\dagger}$ \\
\hline \multicolumn{7}{|l|}{ Control Variables } \\
\hline Children & -0.08 & 0.02 & $-0.13^{*}$ & $-0.18^{* *}$ & 0.12 & -0.02 \\
\hline Negative affect & $0.31^{* * *}$ & $0.47^{* * *}$ & 0.07 & -0.02 & 0.14 & -0.29 \\
\hline Age & 0.02 & -0.04 & 0.08 & 0.02 & $-0.07 *$ & $-0.13 * * *$ \\
\hline Job tenure & -0.01 & $-0.11^{\dagger}$ & -0.06 & 0.01 & $-0.20 * * *$ & $-0.11 * *$ \\
\hline$N$ (couples) & 234 & 218 & 234 & 218 & 205 & 198 \\
\hline$F$ & $5.6^{* * *}$ & $6.72^{* * *}$ & $5.99 * * *$ & $6.61^{* * *}$ & $65.23 * * *$ & $83.02 * * *$ \\
\hline$R^{2 c}$ & 0.33 & 0.39 & 0.35 & 0.39 & 0.15 & 0.18 \\
\hline Adjusted $R^{2}$ & 0.27 & 0.33 & 0.29 & 0.33 & & \\
\hline
\end{tabular}

${ }^{a}$ Figures in columns under Work-Family Conflict and Control over Work are standardized beta coefficients; figures under Turnover Intentions are coefficients from ordered probit model. ${ }^{\dagger}$ Indicates $p<$ 0.10 ; *Indicates $p<0.05$; ** Indicates $p<0.01$; *** Indicates $p<0.001$; HR, human resource.

${ }^{b}$ The control variable was only included in the turnover equations.

"This figure is a "pseudo $R^{2 "}$ in the turnover equations, which were estimated using ordered probit models.

Source: Cornell Couples and Careers Study, 1998-99.

over their working conditions. There is no relationship between salary and any of the three outcomes for wives. The availability of career-development benefits has no impact on any of the outcomes for either husbands or wives. Job security is negatively related to both work-family conflict and turnover intentions for both wives and husbands, however. This result indicates that women and men who 
feel secure in their jobs experience lower levels of work interference with family and are less likely to leave their employers.

The work design block of predictors affects work-family conflict and turnover intentions to a modest degree and has a very strong impact on employee control over work. Decision-making autonomy, flexible technology use, and travel are all strongly and positively related-and work hours is strongly and negatively related-to control for both wives and husbands. In addition, the coefficient for coordination with others is negative and marginally significant, but only for husbands' reported control over work. These results suggest that both men and women who have a high level of autonomy in their jobs, who use technology to stay connected between work and home, and who travel as part of their jobs enjoy high levels of control, whereas those who work long hours report lower levels of control. With respect to work-family conflict, husbands who must coordinate extensively with others in the course of their work report higher levels of work interference with family. For wives, using flexible technology and working longer hours are both associated with more work-family conflict, albeit the coefficients for these variables are only marginally significant. Two variables reach marginal levels of significance in the models predicting turnover intentions: wives whose jobs involve travel and husbands who use technology to stay connected between work and home both tend to report increased plans to leave their employer.

There are very few significant effects of spouse variables in our models. None of the variables measuring spouses' work hours, salary, job security, flexible technology use, or access to flexible scheduling has any effect on the reported work-family conflict of either wives or husbands. One coefficient is significant in the models predicting control over work-wives' use of technology to stay connected between work and home is negatively related to husbands' reported control. In the turnover models, husbands' salary is negatively related to wives' turnover intentions, whereas the coefficient for wives' access to flexible scheduling is marginally significant and negatively related to husbands' turnover intentions.

\section{Summing Up}

This chapter extends previous research on work-life integration by identifying challenges that employees from dual-earner couples face in integrating their work and nonwork lives and by developing a comprehensive model of organizational family responsiveness involving formal and informal policies and practices for work-life support, traditional human resource incentives, and work redesign, all within the context of an organizational culture that values and supports the work-life integration of all employees. We use both qualitative and quantitative data to examine the model. 
The respondents in The Cornell Couples and Careers Study are a group of middle- and upper middle-class employees. For the most part, they are well paid, are well educated, work primarily in professional or managerial occupations, and enjoy a relatively high level of control over their work. Despite these advantages, however, they report a considerable amount of work-family conflict. Analyses of focus-group discussions indicate that many of the work-nonwork conflicts experienced by our couples are time-based. Lack of flexibility in the timing and place of work and excessive time demands hamper the effective integration of work with the rest of life, and the simple availability of benefits and policies designed to provide temporal flexibility does not represent an adequate organizational response to the work-life challenges employees face. In the regression analyses, flexible scheduling policies have no effect on work-family conflict or control over work, but are associated with lower turnover intentions for husbands. Focusgroup results do, however, suggest that employees value flexible scheduling policies and find them useful. Yet although many focus-group participants report having worked out useful flexible scheduling arrangements on an individual basis, the fact that such arrangements are not available across the board constitutes a shortcoming in organizational responsiveness to the challenges of worklife integration. Our qualitative data suggest that employees' access to flexible scheduling is uneven and may depend on the type of work they do, the hierarchical level they occupy in their organizations, and/or the idiosyncratic attitudes of their supervisors.

With respect to informal work-life policies, the importance of supervisor support is quite evident both in the regression and qualitative analyses. Supervisor support is associated with less frequent work-family conflict, with higher levels of control over work for wives, and with decreased turnover intentions for both wives and husbands. Focus-group analyses suggest that supervisors who are helpful and supportive of their employees' family demands tend to engender more gratitude, loyalty, and respect from workers. Yet although supervisor support, like formal policies, is clearly important, it is no magic bullet for dual-earner couples struggling to integrate work and life demands. Informal workplace support from supervisors and formal work-life policies should represent two complementary elements of a family-responsive organization. Although some of the employees in the Cornell study appear to enjoy both types of work-life support, our focus-group data suggest that in some organizations formal and informal elements function in a compensatory rather than complementary manner. For example, the focus groups at the two large manufacturing organizations (Vantech and Transco) indicate that, although these firms have work-life policies on the books, the overall organizational culture is not particularly supportive of work-life integration. By contrast, some of the health-care and educational employers have few formal policies in effect, yet most employees indicate that supportive supervisors grant them the flexibility they need to manage their family and personal responsibilities. 
The qualitative data shed light on the symbolic importance of formal worklife initiatives. Employers who develop, implement, and publicize work-life policies send a signal throughout the organization that work-life issues are important. This signal serves to legitimate employees' desires and efforts to integrate work and nonwork roles and to demand reasonable accommodations from their employers to help them be successful at work and beyond. If the bulk of organizational family responsiveness occurs informally at the level of supervisor discretion, employees may perceive a lack of trust and respect from their employer. This understanding, in turn, may undermine job satisfaction and organizational commitment while creating resentment toward the employer.

Both qualitative and quantitative results provide support for our contention that the difficulties of work-life integration cannot be addressed solely through programs designed to provide flexibility and limit overall work demands. Traditional human resource incentives also play a part. Focus-group results demonstrate that adequate pay and benefits are important components of organizational family responsiveness. For instance, employees identified salary freezes and unsatisfactory health insurance as stressors. Although regression analyses show that salary is positively related to work-family conflict for husbands, we suspect that this may be picking up the fact that highly paid jobs often have a higher overall level of work demands. Salary is also positively related to control over work for husbands, and husbands who report high levels of control over work have significantly lower turnover intentions. The regression analyses also reveal the importance of job security; this variable is associated with less work-family conflict and lower turnover intentions for both wives and husbands. Among dualearner couples, worries about losing a job constitute a work-domain stressor that negatively affects family and personal life. Because two careers must be considered in any episode of job change, our employees may be less mobile than employees without working spouses and therefore place a high value on job security. This suggests that organizations can enhance their employees' work-life integration by emphasizing job security in their human resource practices.

Work design constitutes another dimension of our model of organizational family responsiveness. Both quantitative and qualitative data demonstrate the impact that job demands and work design elements have on the work-life interface. Regression analyses show that long work hours are linked to increased work-family conflict and lower levels of work control, whereas job autonomy increases control over work. Work that requires frequent coordination with other people is associated with more work-family conflict and less control over work for husbands. The use of communication technologies, including cellular phones, faxes, email, and portable computers, gives wives and husbands more control over their work, but is also associated with more work-family conflict for wives. This may be due to the fact that the use of these technologies allows the demands and pressures from the work domain to intrude into the home itself. Focus-group 
results also highlight some of the ways in which work design affects work-life integration. Frequent meetings and inflexible work schedules both impair employees' ability to mesh work and life harmoniously. For instance, some employees describe how rigid manufacturing work processes prevent them from being able to modify their work schedules in order to meet family demands. Others report having coworkers who expect them to be continuously available for meetings, even early in the morning or in the evening, thereby reinforcing workplace cultures of overwork.

Organizations must be vigilant and responsive to the problem of overwork. Our qualitative data show that crushing workloads (often resulting from organizational downsizing and the redistribution of tasks to fewer employees) and workplace norms that demand long work hours constitute serious barriers to satisfactory work-life integration. Although several of the organizations in the Cornell study have a number of flexible scheduling and other work-life policies on the books, these employers have made little progress in institutionalizing reasonable limits on work time demands. Workplace norms that demand extensive "face time" undermine and limit the effectiveness of formal work-life policies. One employee in the focus groups even reported electing a part-time work schedule, with reduced pay and benefits, in order to limit herself to a regular full-time workweek. Such individualized solutions to the challenges of work-life integration clearly indicate that organizations are failing to systematically meet employees' work-life needs.

All in all, the results of the study reported in this chapter provide support for the argument that organizational family responsiveness involves multiple elements. Formal work-life policies, informal work-life support from supervisors and other organizational members, favorable human resource incentives, and work designed to provide employees with a reasonable level of work demands and a high level of control over the conditions of their work are all important for supporting employee work-life integration. Our qualitative data suggest that a workplace culture of family responsiveness is also a critical element and that barriers to effective work-life integration derive in part from organizational cultures that fail to appreciate the importance of employees' family and personal lives. Unequal access to flexible scheduling, unreasonable work demands, inadequate compensation and benefits, job insecurity, and employees' often having to take on primary responsibility for presenting a convincing case to their employers that they should be granted flexibility all signal a lack of systematic respect for employees' personal and family needs. In order to fully address the challenges of work-life integration, there must be support from all levels of the organization, from the CEO on down through the ranks. Only when employers truly believe that systematic work-life integration constitutes a win-win situation for themselves and their employees and back this belief up with policies and programs to 
give employees flexibility, limit work demands, and provide adequate human resource incentives will the promise of work-life integration be realized.

This chapter has implications for future research on work-life integration. Rather than focusing on a limited set of work-life policies, we have advanced and tested a broader, more integrated model of factors that affect employees' worklife integration. We urge future researchers to continue in this vein by measuring multiple elements of formal and informal work-life supports, traditional human resource incentives, work design, and organizational culture. Our regression analyses also reveal some interesting gender differences in the prediction of workfamily conflict, control over work, and turnover intentions that are deserving of further research. Finally, although we do not find many significant effects of spouses' work characteristics and work-life supports on husbands' or wives' outcomes, we encourage future scholars to take a couple-level approach to the study of work-life integration in dual-earner couples. It is possible, for instance, that the work-life supports that husbands and wives enjoy in their workplaces could have either an additive or multiplicative effect on work-life integration at the couple level. To the extent that future research can identify the combination of workplace characteristics and work-life supports that best enhance work-life integration for dual-earner couples, employers, employees and their families all stand to benefit. 